\title{
Anomerization of Acrylated Glucose During Traveling Wave Ion Mobility Spectrometry
}

\author{
Christophe Chendo, ${ }^{1}$ Guillaume Moreira, ${ }^{1}$ Aura Tintaru, ${ }^{1}$ Paola Posocco, ${ }^{2,3}$ Erik Laurini, ${ }^{2,3}$ \\ Catherine Lefay, ${ }^{1}$ Didier Gigmes, ${ }^{1}$ Stéphane Viel, ${ }^{1}$ Sabrina Pricl, ${ }^{2,3}$ Laurence Charles ${ }^{1}$
}

${ }^{1}$ Aix-Marseille Université - CNRS, UMR 7273, Institut de Chimie Radicalaire, Marseille, France

${ }^{2}$ Molecular Simulation Engineering (MOSE) Laboratory, Department of Engineering and Architecture (DEA), University of Trieste, Trieste, Italy

${ }^{3}$ National Interuniversity Consortium for Material Science and Technology (INSTM), Research Unit MOSE-DEA, University of Trieste, Trieste, Italy

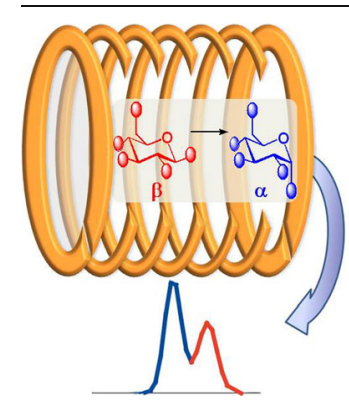

\begin{abstract}
Anomerization of simple sugars in the liquid phase is known as an acidand base-catalyzed process, which highly depends on solvent polarity. This reaction is reported here to occur in the gas phase, during traveling wave ion mobility spectrometry (TWIMS) experiments aimed at separating $\alpha$ - and $\beta$-anomers of penta-acrylated glucose generated as ammonium adducts in electrospray ionization. This compound was available in two samples prepared from glucose dissolved in solvents of different polarity, namely tetrahydrofuran (THF) and $N, N$ dimethylacetamide (DMAC), and analyzed by electrospray tandem mass spectrometry (ESI-MS/MS) as well as traveling wave ion mobility (ESI-TWIMS-MS). In MS/MS, an anchimerically-assisted process was found to be unique to the electrosprayed $\alpha$ -
\end{abstract} anomer, and was only observed for the THF sample. In ESI-TWIMS-MS, a signal was measured at the drift time expected for the $\alpha$-anomer for both the THF and DMAC samples, in apparent contradiction to the MS/MS results, which indicated that the $\alpha$-anomer was not present in the DMAC sample. However, MS/MS experiments performed after TWIMS separation revealed that ammonium adducts of the $\alpha$-anomer produced from each sample, although exhibiting the same collision cross section, were clearly different. Indeed, while the $\alpha$-anomer actually present in the THF sample was electrosprayed with the ammonium adducted at the C2 acrylate, its homologue only observed when the DMAC sample was subjected to TWIMS hold the adducted ammonium at the $\mathrm{C} 1$ acrylate. These findings were explained by a $\beta / \alpha$ inter-conversion upon injection in the TWIMS cell, as supported by theoretical calculation and dynamic molecular modeling.

Key words: TWIMS, Substituted glucose, lon heating, Anomerization, Anchimeric assistance, MS/MS

Received: 2 February 2015/Revised: 16 April 2015/Accepted: 18 April 2015/Published Online: 4 June 2015

\section{Introduction}

$\mathrm{W}$ ith the advent of commercially available instruments in the last decade, ion mobility spectrometry (IMS) combined with mass spectrometry (MS) has become a routine technique to separate individual molecules produced as naked ions in the gas phase, and subsequently gain useful details

Electronic supplementary material The online version of this article (doi:10.1007/s13361-015-1170-6) contains supplementary material, which is available to authorized users.

Correspondence to: Sabrina Pricl; e-mail: sabrina.pricl@di3.units.it, Laurence Charles; e-mail: laurence.charles@univ-amu.fr about their conformation. As a result, IMS-MS has increasingly been used to study the dynamics of macro(bio)molecules in the gas phase [1-4]. In contrast to devices operated at the low electric field limit [5] such as linear field drift tube (DT) ion mobility cell [6], commercial instruments employing the traveling wave technology [7, 8] involve intense electric fields. However, use of intense electric fields to achieve ion separation in traveling wave IMS (TWIMS) raises the issue of altering ion conformation during IMS analysis. Using a variety of thermometer ions for which dissociation energy was accurately characterized, the extent to which ions are heated along their pathway has been determined for different generations of TWIMS instruments [9-12]. These studies concluded that ion activation mostly occurred during their injection in the mobility 
cell, whereas collisions experienced during their drift inside the mobility cell allowed ions to be cooled down to some extent. On the one hand, controlled heating of gas-phase ions can be advantageously used to explore the conformational landscape of species on their way to dissociation [13]. On the other hand, careful optimization of experimental settings is mandatory to minimize ion activation when aiming at characterizing their original conformation, although this may sometimes compromise either sensitivity or IMS resolution [9, 12, 14, 15]. Such optimization is particularly important in the case of small ionic species because of their low number of vibrational degrees of freedom often associated with a low barrier for interconversion.

Here, we report a case where ion activation in TWIMS was observed to induce a change in configuration of substituted glucose, the $\alpha$ anomer being generated in the gas phase from the $\beta$ anomer. The studied $n$-acrylated glucose compounds, referred to as Glu-nA with $\mathrm{n}$ the number of grafted acrylate groups (Scheme 1), were obtained in the attempt of grafting polystyrene blocks onto cellulose to modify the properties of this natural polymer. Specifically, the first step of the synthesis protocol consists of functionalizing $\mathrm{OH}$ groups of the saccharidic skeleton with an acrylate moiety, prior to performing 1,2-addition of an alkoxyamine onto the acrylate to further allow nitroxide-mediated polymerization [16] of styrene (see Supplementary Information). D-Glucose was used as a model substrate in preliminary experiments aimed at selecting the best solvent to be employed for the acrylation reaction, i.e., dimethylacetamide (DMAC) or tetrahydrofuran (THF).

\section{Material and Methods}

\section{Chemicals}

D-Glucose (99.5\%), triethylamine $\left(\mathrm{Et}_{3} \mathrm{~N}, 99+\%\right)$, acryloyl chloride $(97+\%)$, lithium chloride $(\mathrm{LiCl}, 99+\%)$, and $N, N$ dimethylacetamide (DMAC, 99.5+\%) were purchased from Sigma Aldrich (St. Louis, MO, USA). Sodium chloride $(\mathrm{NaCl})$ and dichloromethane were from Carlo Erba (Val de

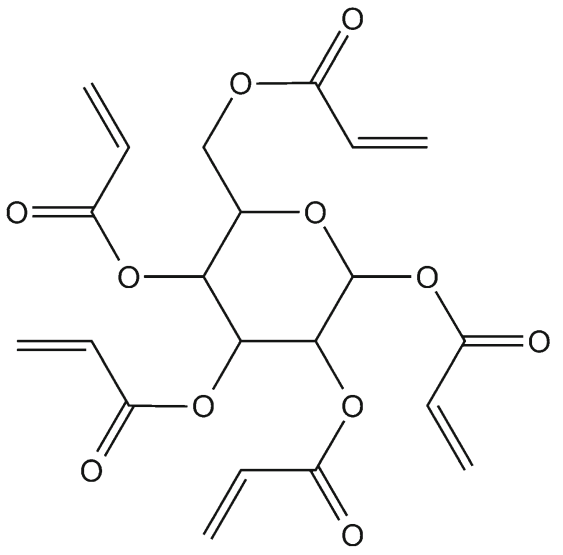

Glu-5A

Scheme 1. Structure of the fully acrylated glucose, Glu-5A
Reuil, France), while hydrochloric acid ( $\mathrm{HCl}, 37 \%)$ was from Acros Organics (Thermo Fisher Scientific, Geel, Belgium). Tetrahydrofuran (THF, purex for analysis) from SDS (Peypin, France) was distilled over sodium before use. For MS experiments, methanol was from SDS, and ammonium acetate and polyalanine were from Sigma Aldrich. Unless specified, all chemicals were used as received without further purification.

\section{Synthesis}

Acrylated glucose was synthesized as follows using two different reaction media. In THF: D-Glucose $\left(1 \mathrm{~g} ; 5.55 \times 10^{-3} \mathrm{~mol}\right)$ and $\mathrm{Et}_{3} \mathrm{~N}\left(0.85 \mathrm{~mL} ; 6.11 \times 10^{-3} \mathrm{~mol}\right)$ were mixed in $6 \mathrm{~mL}$ of anhydrous THF and the solution was deoxygenated by argon bubbling at $0^{\circ} \mathrm{C}$ for $15 \mathrm{~min}$. Acryloyl chloride $(0.45 \mathrm{~mL}$; $5.55 \times 10^{-3} \mathrm{~mol}$ ) was then added dropwise at $0^{\circ} \mathrm{C}$ under stirring. After one night of stirring at room temperature, hydrolysis with $\mathrm{HCl}(11 \mathrm{~mL})$ and four extraction steps with dichloromethane (with $\mathrm{NaCl}$-saturated aqueous phase in the two last steps), the organic phase was dried over $\mathrm{MgSO}_{4}$. The product was finally recovered after evaporation of dichloromethane. In DMAC: DGlucose $\left(1 \mathrm{~g}\right.$; $\left.5.55 \times 10^{-3} \mathrm{~mol}\right)$ was first dissolved in $6 \mathrm{~mL}$ of DMAC supplemented with $\mathrm{LiCl}(150 \mathrm{mg} ; 0.59 \mathrm{M})$ at $80^{\circ} \mathrm{C}$. After addition of $\mathrm{Et}_{3} \mathrm{~N}\left(3.9 \mathrm{~mL} ; 27.8 \times 10^{-3} \mathrm{~mol}\right)$ at room temperature, the solution was cooled at $0^{\circ} \mathrm{C}$ and deoxygenated by argon bubbling. Acryloyl chloride $\left(2.25 \mathrm{~mL} ; 27.8 \times 10^{-3} \mathrm{~mol}\right)$ was then added dropwise at $0^{\circ} \mathrm{C}$. After stirring overnight at room temperature, the solution was filtrated to eliminate solid $\mathrm{Et}_{3} \mathrm{NHCl}$ salt.

\section{Mass Spectrometry and Ion Mobility Spectrometry}

High resolution MS, MS/MS and traveling wave ion mobility mass spectrometry (TWIMS-MS) experiments were performed with a Waters Synapt G2 HDMS quadrupole/time-of-flight (QTOF) tandem mass spectrometer (Manchester, UK). Both THF and DMAC samples were diluted $(1 / 10, \mathrm{v} / \mathrm{v})$ in methanol supplemented with ammonium acetate $(3 \mathrm{mM})$, and introduced at a $10 \mu \mathrm{L} \mathrm{min}^{-1}$ flow rate in the electrospray ionization source operated in the positive mode (capillary voltage: $+2.8 \mathrm{kV}$; sampling cone voltage: $+20 \mathrm{~V}$ ) under a desolvation gas $\left(\mathrm{N}_{2}\right)$ flow of $100 \mathrm{~L} \mathrm{~h}^{-1}$ heated at $35^{\circ} \mathrm{C}$. IMS-MS spectra were all recorded in the $50-1200 \mathrm{~m} / \mathrm{z}$ range, with trap bias DC voltage of $35 \mathrm{~V}$, helium cell gas flow of $180 \mathrm{~mL} \mathrm{~min}$, and the TWIM $\mathrm{S}$ cell operated at $3.45 \mathrm{mbar}$ of $\mathrm{N}_{2}$ with the following wave parameters: $650 \mathrm{~m} \mathrm{~s}^{-1}$ wave velocity and $35 \mathrm{~V}$ wave height. IMS-MS/MS experiments were performed at a $3 \mathrm{eV}$ collision energy (laboratory frame), whereas product ions generated in the ion trap were obtained at a $10 \mathrm{eV}$ collision energy (laboratory frame), using argon as the collision gas in both cases. Data analyses were conducted using the MassLynx 4.1 and DriftScope 2.1 programs provided by Waters. The drift timescale of the TWIMS-MS experiments was converted to a collision cross-section scale, following the calibration procedure described by Smith et al. [17]. 


\section{Theoretical Calculations}

MD Simulations of Glucose Derivatives All classical molecular dynamics (MD) simulations discussed in this work were performed with the GPU version of pmemd (pmemd.cuda) implemented in AMBER14 [18] on the EURORA GPU-CPU supercomputer (CINECA, Bologna, Italy), using the new version of the GLYCAM06 force field [19]. Eventual missing force field terms were derived exploiting the Antechamber module of AMBER14 consistently with General Amber Force Field (GAFF) [20]. Newton's equations of motion were integrated using the leapfrog scheme with a time step of $2 \mathrm{fs}$. All bond lengths were constrained by application of the SHAKE algorithm [21] with a relative geometric tolerance of $10^{-4}$. The structures of each glucose isomer were immersed in a box of THF or DMAC molecules, respectively. In the last case, a suitable number of $\mathrm{Li}^{+}$and $\mathrm{Cl}^{-}$ions were also added to solvent box. Non-bonded interactions were handled using a twin-range cutoff scheme with short- and long-range cutoff radii of 0.8 and $1.4 \mathrm{~nm}$, respectively, and an update frequency of 5 time-steps for the short-range pair-list and intermediaterange interactions. Solute and solvent degrees of freedom were independently coupled to a heat bath [22] at $300 \mathrm{~K}$, with a relaxation time of $0.1 \mathrm{ps}$. The box dimensions were isotropically coupled to a pressure bath [23] at $1 \mathrm{~atm}$, with a relaxation time of $0.5 \mathrm{ps}$. The center of mass motion was removed every 2 ps. For each glucose derivative considered, the solute was placed in a truncated-octahedron box with a minimum solute-to-wall distance of $1.6 \mathrm{~nm}$. To relax the system, a steepest-descent energy minimization was performed with positionally constrained ring atoms, followed by $100 \mathrm{ps}$ MD equilibration prior to production. For all MD simulations, production was carried out for $200 \mathrm{~ns}$, saving trajectory frames every 0.5 ps for analysis.

Calculations of CCS from MD Data For CCS calculations of the ammonium adducts of the glucose derivatives, 20 equilibrated configurations for each molecule were extracted from the relevant MD trajectories. For each configuration, the $\mathrm{NH}_{4}{ }^{+}$ moiety was positioned in all possible different positions around the derivatized glucose ring; then, the resultant complexes were geometry optimized and hence subjected to $20 \mathrm{~ns}$ MD simulations in vacuum. A built-in distance restraint, $10-15 \AA$ from the nearest atom of the sugar molecules, was applied so that they did not "dissociate" during the course of the simulation. In this way, 600 candidate structures were generated including each possible $\mathrm{NH}_{4}{ }^{+}$placement and glucose derivative (either $\alpha$ - or $\beta$ anomer) to obtain a meaningful statistical representation of the relevant CCS. The collisional cross-section value for each structure was calculated using the standard sigma projection method by averaging over all relevant MD equilibrated configurations. In brief, CCSs were obtained according to the method suggested by Dear et al. [24] and the open source software MOBCAL (http://www.indiana.edu/ nano/ software.html) [25], using the 3D coordinate data sets extracted from the MD trajectories. The 12-6 parameter set recently developed by Siu et al. [26] for $\mathrm{He}, \mathrm{H}, \mathrm{C}, \mathrm{N}$, and $\mathrm{O}$ atoms were adopted.

Car-Parrinello Molecular Dynamics Simulations All simulations were performed using the CPMD package (v. 3.15.1.22) [27], which implements the Car-Parrinello scheme for ab initio MD calculations [28]. Car-Parrinello MD simulations implement density functional theory using a plane-wave basis set and pseudo-potentials for the core electrons. The Perdew-Burke-Ernzerhof generalized gradient approximation [29] together with the norm-conserving Troullier Martins pseudopotentials [30] were adopted. The Kohn-Sham orbitals [31] were expanded in plane waves with the energy cutoff 100 Ry. Only the $\Gamma$-point was used for integration over the Brillouin zone in the reciprocal space. Periodic boundary conditions were used to eliminate surface effects. For each adduct, the initial atomic configurations were taken from the corresponding equilibrated classical MD simulations. The size of the simulation cell was $18 \times 18 \times 18 \AA^{3}$, allowing more than $3 \AA$ space between the outermost atom and the border of the simulation cell to avoid any artifacts. Every atom in the simulation system was treated quantum-mechanically. Calculations were performed with spin polarization on, and the ground state spin multiplicity of the system was taken as 4 . The Nosé-Hoover chain thermostat was used for controlling ionic and electronic temperatures. The frequency for the ionic thermostat was set to $1800 \mathrm{~cm}^{-1}$ (characteristic of a C-C bond vibration frequency) and for the electron thermostat to $10,000 \mathrm{~cm}^{-1}$. The fictitious electron mass parameter in CPMD was set to 400 a.u. Short MD runs without thermostat were carried out to estimate the approximate value around which the fictitious electronic kinetic energy oscillates. Based on the observations from these runs, a value of 0.01 a.u. was chosen for the electronic kinetic energy, while the MD time-step was set to 0.0964 fs. Geometry optimization was performed on the system before $\mathrm{MD}$, and the system was equilibrated for 1 ps. Energies, including the fictitious electronic kinetic energy, were monitored throughout the simulation to ascertain that the system does not deviate from the Born-Oppenheimer surface during the MD simulation. MD trajectories were visualized using the VMD software [32].

\section{Results and Discussion}

As mentioned in the Introduction, D-glucose was used as a model substrate in preliminary experiments aimed at optimizing the functionalization of $\mathrm{OH}$ groups in a saccharidic skeleton with an acrylate moiety and, more particularly, selecting the best solvent to be employed for this acrylation reaction, i.e., dimethylacetamide (DMAC) or tetrahydrofuran (THF). For the sake of clarity, these samples are herein designated as "DMAC sample" and "THF sample," respectively, although they were diluted (dilution factor $1 / 10, v / v$ ) with methanol to ensure their 
ionization by electrospray. Although the amount of acryloyl chloride reagent was carefully optimized to favor a unique acrylation degree for glucose, positive mode ESI-MS experiments performed on raw samples always revealed mixtures of Glu-nA species together with unreacted glucose (Supplementary Figure S1), regardless of the solvent used for the synthesis. Signals measured for cationic adducts of Glu-nA (with $n=3-5$ ) were, however, of much lower intensity in the case of the THF sample, consistent with the lower solubility of glucose in this solvent compared with DMAC. Nevertheless, accurate mass measurements could be performed to support these assignments (Supplementary Tables S1-S2) and MS/MS data of good quality were obtained from both samples. While Glu-nA compounds could be ionized using a variety of cations, including alkali, the most intriguing data discussed here were obtained in the case of ammoniated molecules.

\section{CID of $\left[\mathrm{Glu}-\mathrm{nA}+\mathrm{NH}_{4}\right]^{+}$as a Function of the Solvent Used for the Glu-nA Synthesis}

Ammonium adducts of Glu-3A ( $/ 2 / z$ 360.1), Glu-4A $(\mathrm{m} / \mathrm{z}$ 414.1), and Glu-5A ( $\mathrm{m} / \mathrm{z}$ 468.2) generated upon ESI of both samples were subjected to collision-induced dissociation (CID) experiments (Figure 1). These MS/MS spectra exhibited the same main product ions (all measured at odd $\mathrm{m} / \mathrm{z}$ values, i.e., no longer containing the adducted ammonium) but with different relative abundance depending if the sample was prepared in DMAC (Figure 1, left) or THF (Figure 1, right). In addition, several additional minor peaks were observed upon CID of precursor ions originating from the THF sample. These results suggested that different structural isomers were produced depending on the solvent used during the acrylation step.

As supported by accurate mass measurements (Supplementary Tables S3-8) and $\mathrm{MS}^{3}$ experiments (Supplementary Figure S2), main product ions were found to usefully confirm the acrylation degree $\mathrm{n}$ of precursor ions. For partially substituted glucose (Glu-nA with $n=3$ or 4 ), MS/MS data allow the number of acrylate moieties to be determined from the number of acrylic acid molecules (72 Da) successively eliminated from the precursor ion, the first one being released together with ammonia (89 Da). This reaction generates product ions designated with an open diamond in the MS/MS spectrum of [Glu-3A $\left.+\mathrm{NH}_{4}\right]^{+}$(Figure 1, top) and of [Glu-4A $\left.+\mathrm{NH}_{4}\right]^{+}$(Figure 1, middle). In contrast, only three acrylic acid molecules were observed to be eliminated in a successive manner from [Glu-5A $\left.+\mathrm{NH}_{4}\right]^{+}$(Figure 1, bottom), suggesting a key role of the remaining $\mathrm{OH}$ group(s) in partially acrylated glucose for the whole dissociative sequence to occur (Supplementary Scheme S2). An alternative fragmentation reaction clearly involving one hydroxyl moiety (and hence not observed in the case of Glu-5A) consists of a concerted release of water and ammonia (35 Da) from the precursor ion. Fragments so-formed were detected at $\mathrm{m} / \mathrm{z} 325.1$ and 379.1 for Glu-3A and Glu-4A, respectively, and further experience successive eliminations of acrylic acid, leading to the product ion series designated with an open square in Figure 1.

Amongst additional signals observed in the case of the THF sample, a unique feature is the presence of a peak

Glu-nA synthesized in DMAC

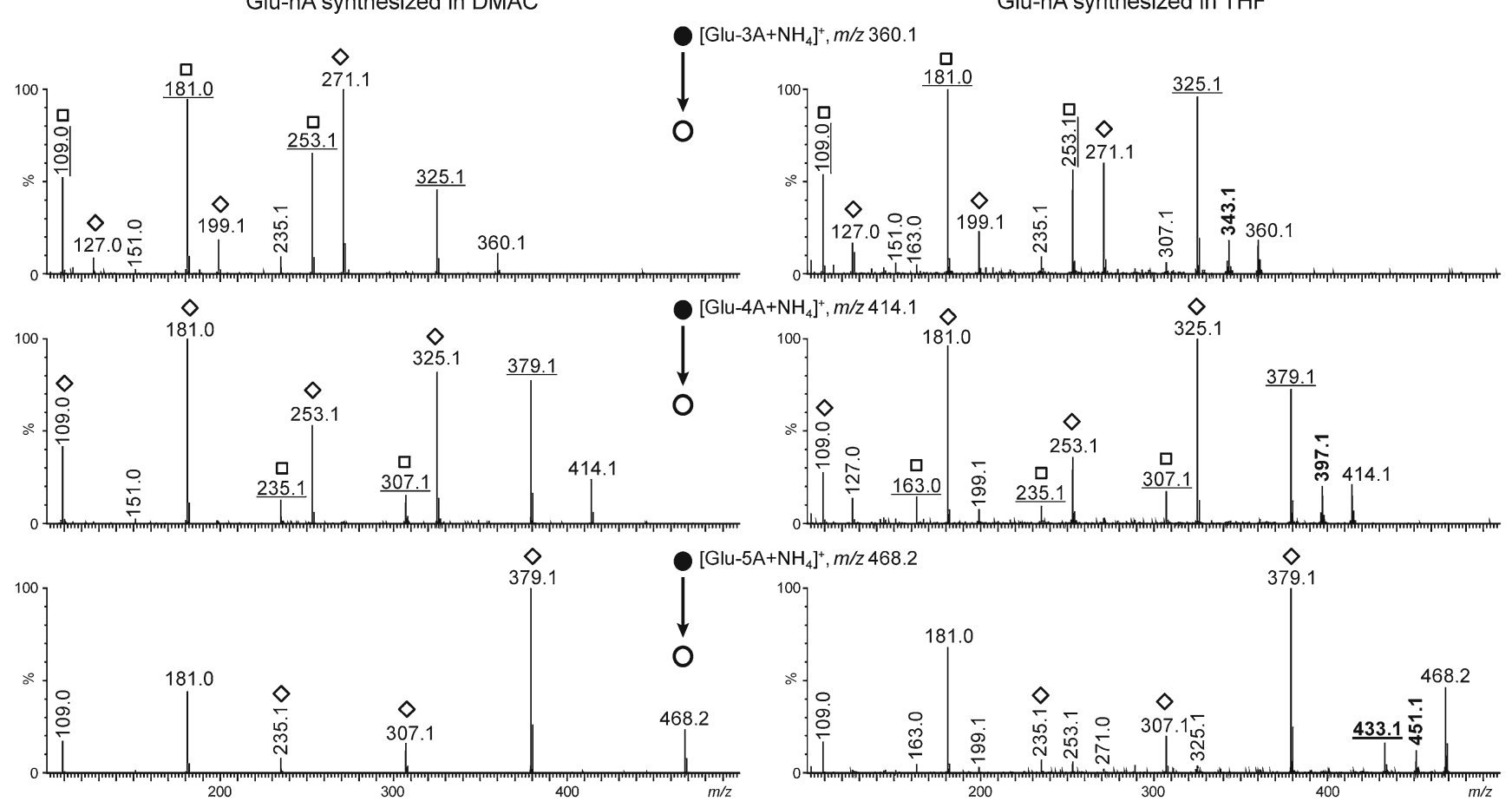

Figure 1. ESI-MS/MS spectra (3 eV collision energy, laboratory frame) of ammonium adducts of Glu-3A (top), Glu-4A (middle), and Glu-5A (bottom), synthesized in DMAC (left) or in THF (right). For the sake of clarity, accurate mass measurements of product ions are listed in Supplementary Tables S3-S8 
corresponding to the protonated molecule, obtained when the precursor ion has eliminated ammonia only. This peak is observed at $m / z 343.1$ for $\left[\mathrm{Glu}-3 \mathrm{~A}+\mathrm{NH}_{4}\right]^{+}$(Figure 1 right, top), at $\mathrm{m} / \mathrm{z} 397.1$ [Glu-4A $\left.+\mathrm{NH}_{4}\right]^{+}$(Figure 1 right, middle), and at $\mathrm{m} / \mathrm{z} 451.2$ [Glu-5A $\left.+\mathrm{NH}_{4}\right]^{+}$(Figure 1 right, bottom). These results suggest that a particular structural isomer of Glu-nA is formed solely in THF and exhibits a special stability as a protonated molecule when generated from the ammonium adduct. More intriguingly, in the case of Glu-5A, the protonated molecule so-formed was observed to release a water molecule, as indicated by the $\mathrm{m} / \mathrm{z} 433.1$ product ion, although Glu-5A does not contain any hydroxyl group. Overall, these MS/MS data strongly suggested that different structural isomers of Glu-nA were formed depending on the solvent used in the synthesis. In particular, THF would promote the formation of one form, which does not exist in the sample obtained from the DMAC medium. For partially substituted glucose, different positional isomers can be envisaged and might contribute to differences observed in MS/MS spectra of the two samples. Instead, data obtained in the case of fully substituted glucose led us to consider anomers of Glu-5A.

A main difference between the two solvents used for the synthesis of Glu-nA is their polarity, indeed known to influence the equilibrium between $\alpha$-glucose and $\beta$-glucose in solution, with a polarity parameter $\left(\mathrm{E}_{\mathrm{T}}(30)=1.000\right.$ for water $)$ of 0.377 for DMAC and of 0.207 for THF [33]. In the liquid phase, anomerization of simple sugars is acid- and base-catalyzed and leads at equilibrium to a mixture of different forms, the composition of which is highly solvent-dependent $[34,35]$. In our case, although ${ }^{1} \mathrm{H}$ NMR could determine the $\alpha / \beta$ ratios of the initial glucose solutions, it could not be used to monitor the actual Glu-nA anomeric composition of the two raw samples under study, which were mixtures of Glu-nA components together with unreacted glucose (yielding complex and inextricable ${ }^{1} \mathrm{H}$ NMR spectra). As expected, the $\alpha / \beta$ anomer ratios of glucose were very different depending on the solvent, with $\alpha / \beta$ anomer ratios of 44.4:55.6 in DMAC- $d_{9}$ and of 83.3:16.7 in THF- $d_{8}$ (Supplementary Figure S3). Although these data clearly showed that anomeric composition of glucose solutions subjected to the acrylation step was very different depending on the solvent, they could not be used to decipher $\alpha / \beta$ anomer ratios of each Glu-nA reaction product for a variety of reasons, amongst which were potential anomeric effect during glucose acrylation (as often observed for substituted sugars [36]), suppression effects during ESI of such raw samples, or differential ionization yield of each species.

Conformational analysis of all Glu-nA in both solvents showed that all compounds (both $\alpha$ - and $\beta$-anomers) remained in the ${ }^{4} \mathrm{C}_{1}$ chair conformation during most of the simulation time, whilst the ${ }^{1} \mathrm{C}_{4}$ chair conformation was never observed. Alternative ring conformations were encountered in (on average) about $0.5 \%$ of the sampled configurations, including $0.05 \%$ of a ${ }^{3,0} \mathrm{~B}$ boat, the remaining $0.45 \%$ being twisted conformations (i.e., neither chair nor boat). Accordingly, possible contributions of different conformers to MS spectra could be ruled out. A main difference between ammonium adducts of Glu-5A anomers was revealed by CP MD simulations: while the adduct featuring the cation complexed to the acrylate at $\mathrm{C} 2$ (Figure 2a) was the most favorable of all other complexes involving $\alpha$-Glu-5A (-33.26 kcal/mol, see also Supplementary Figure S4), the most favorable complex in the case of $\beta$-Glu-5A was the one involving the acrylate at $\mathrm{C} 1$ (Figure $2 \mathrm{~b}$ and Supplementary Figure S4).

Accordingly, a mechanism allowing consecutive elimination of ammonia and water could be proposed in the case of $\alpha$ Glu-5A. As depicted in Scheme 2a with dashed arrows, an anchimerically-assisted process [37-41], occurring here via a nucleophilic attack of one oxygen atom from the acrylate moiety in $\mathrm{C} 1$ onto the carbonyl carbon of the acrylate group in $\mathrm{C} 2$ would allow elimination of $\mathrm{NH}_{3}$ from the precursor ion to produce a stable $\mathrm{m} / \mathrm{z} 451.1$ fragment. The newly created $\mathrm{OH}$ group in this product ion would further be eliminated as a water molecule upon a 1,6-proton transfer, yielding the $m / z 433.1$ product ion. In contrast, release of $\mathrm{NH}_{3}$ alone cannot be envisaged from the ammonium adduct of $\beta$-Glu-5A because the uptake of the proton by the oxygen atom of one acrylate carbonyl group should induce a concerted electron cascade resulting in the release of acrylic acid, yielding the $\mathrm{m} / \mathrm{z} 379.1$

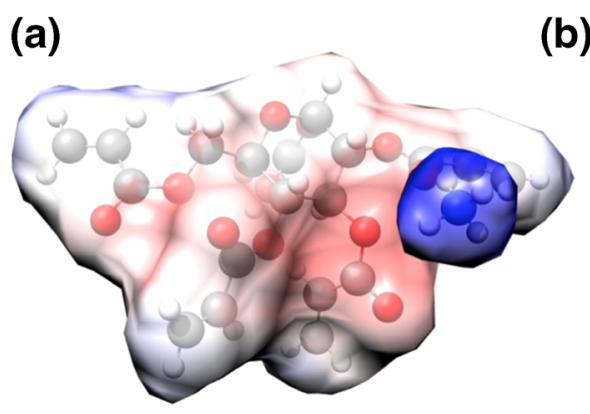

(b)

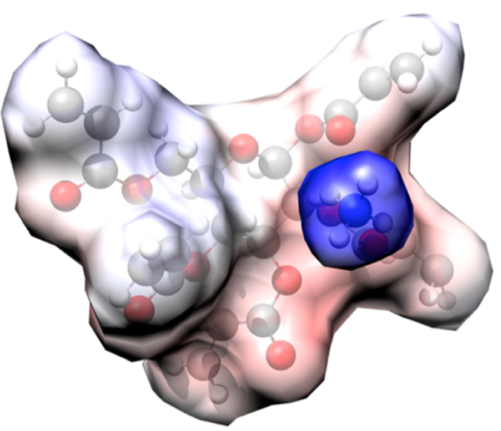

Figure 2. Molecular dynamics equilibrated models of the most favorable ammonium adducts for (a) $\alpha$-anomer and (b) $\beta$-anomer of Glu-5A. Atoms are colored by atom type (C, gray; O, red; N, blue; $\mathrm{H}$, white). Glu-5A is shown in sticks-and-balls, whereas the ammonium ion is shown as spheres. The van der Waals surfaces of Glu-5A and ammonium for both adducts are also shown and colored according to the molecular electrostatic potential (red, highly negative potential; white, neutral potential; blue, highly negative potential) 
product ion (Scheme 2b). In the case of $\alpha$-Glu-5A, the concerted loss of ammonia and acrylic acid can also occur (Scheme 2a, plain arrows) but conducted to a $m / z 379.1$ product ion with a different structure compared with the one arising from $[\beta-\mathrm{Glu}-$ $\left.5 \mathrm{~A}+\mathrm{NH}_{4}\right]^{+}$, possibly contributing to different peak relative intensities as measured in MS/MS spectra (Figure 1) due to consecutive dissociation of the $m / z 379$ product ion (see $\mathrm{MS}^{3}$ spectra in Supplementary Figure S2).

Overall, consecutive losses of ammonia and water would be diagnostic reactions of ammoniated $\alpha$-Glu-5A with the adducted ammonium being located on the acrylate moiety at
C2. Accordingly, MS/MS data indicated that the $\alpha$-Glu-5A anomer was mainly present in the THF sample and remained undetected in the DMAC sample.

\section{Ion Mobility Separation of $\alpha$ and $\beta$ Anomers of $\left[\mathrm{Glu}-5 \mathrm{~A}+\mathrm{NH}_{4}\right]^{+}$}

To further support the assumption that a very different $\alpha / \beta$ ratio in the studied samples could account for differences during CID of ammonium adducts of Glu-5A prepared in different solvents, IMS experiments were performed to tentatively (a) $\left[\alpha-D-G l u-5 \mathrm{~A}+\mathrm{NH}_{4}\right]^{+}$

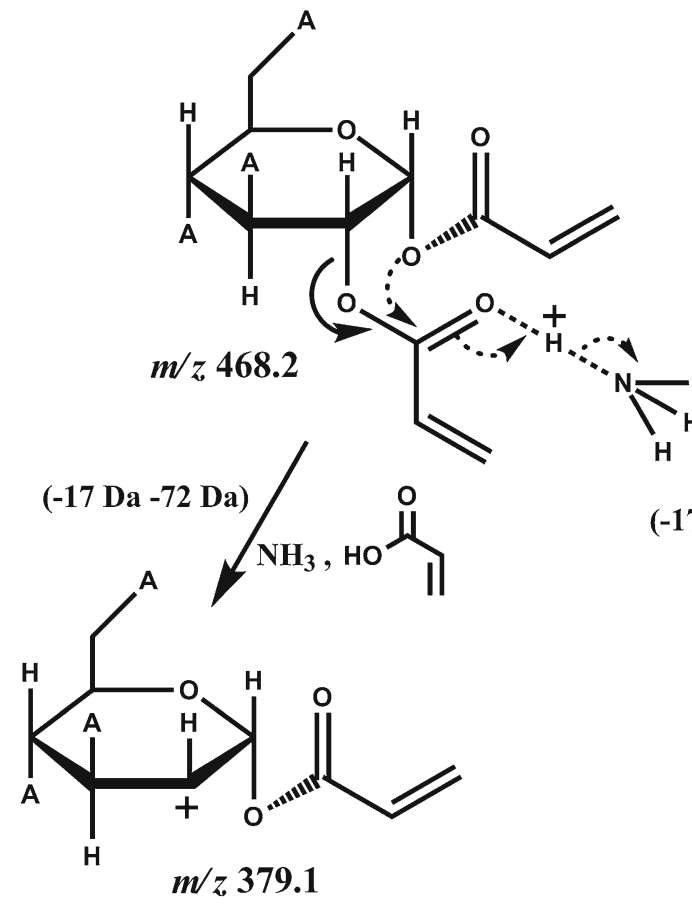

(b) $\left[\beta-D-G l u-5 \mathrm{~A}+\mathrm{NH}_{4}\right]^{+}$

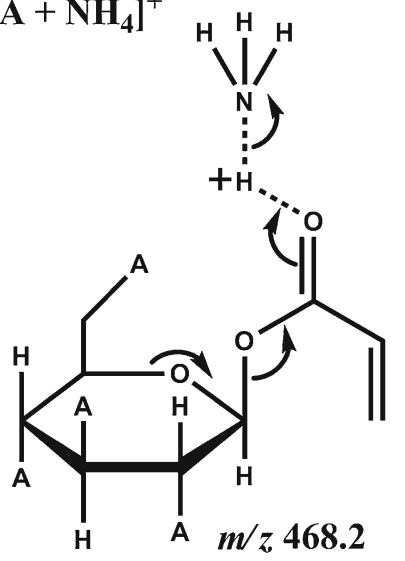

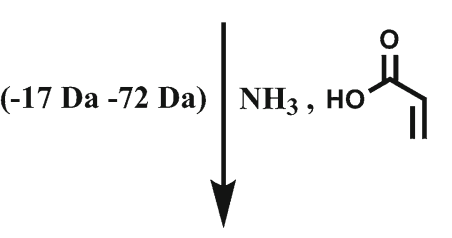

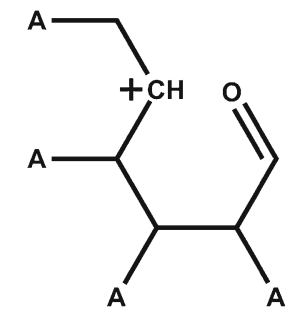

$m / z 379.1$
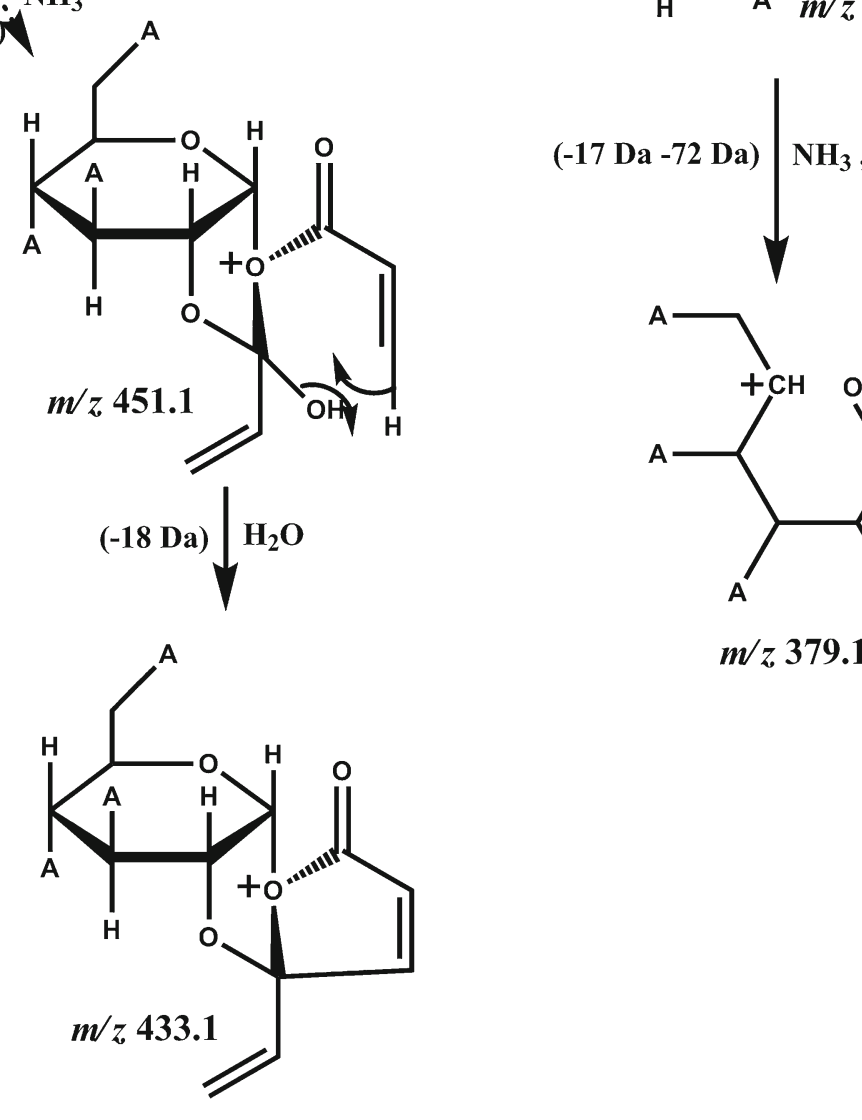

Scheme 2. Proposed mechanisms for the release of ammonia (a) alone or together with acrylic acid from the ammonium adduct of a-Glu-5A (with $\mathrm{NH}_{4}{ }^{+}$on acrylate at C2); (b) alone from the ammonium adduct of $\beta-\mathrm{Glu}-5 \mathrm{~A}$ (with $\mathrm{NH}_{4}{ }^{+}$on acrylate at $\mathrm{C} 1$ ) 
separate the two anomers. Indeed, besides its ability to distinguish conformers, TWIMS is also powerful at separating structural isomers of small gas phase ions, as reported for anomers and epimers of monosaccharide methyl glycosides [42], cistrans isomers of terpyridine derivatives [43], as well as a variety of diastereoisomers [44-47].

The DMAC and THF samples were subjected to ESITWIMS-MS experiments where all ions generated during electrospray were injected into the TWIMS cell prior to be mass analyzed in the oa-TOF mass analyzer. Data related to the [Glu$\left.5 \mathrm{~A}+\mathrm{NH}_{4}\right]^{+}$ions are presented in Figure 3, showing that the arrival time distribution (ATD) of the $m / z 468.2$ ion exhibited two peaks measured at $t_{D}=5.2 \mathrm{~ms}$ and $t_{D}=5.5 \mathrm{~ms}$ for the two samples.

Using a calibration procedure based on singly protonated polyalanine [48], experimental CCS values were estimated from drift times measured after IM separation. As recently reported, the use of IMS calibrants from a different chemical class compared with the analyte can lead to biased CCS results [49]. Although the calibration procedure based on polyalanine may not be the best one to determine highly accurate CCS values for the studied compounds, it is expected to provide relative CCS of the two Glu-5A anomers, hence allowing the two IMS peaks of Figure 3 to be safely assigned. Experimental CCS values were $202 \AA^{2}$ for the first peak and $207 \AA^{2}$ for the second peak ( $\pm 3 \AA^{2}$ in both cases). These data were found to be consistent with CCS calculated for each Glu-5A anomer adducted with ammonium, with a slightly more compact conformation for the $\alpha$ anomer $\left(201.3 \pm 1.3 \AA^{2}\right)$ compared with the $\beta$ one $\left(209.2 \pm 1.4 \AA^{2}\right)$. It should be noted that for each Glu-5A anomer, no significant difference was found between calculated CCS values as a function of the location of the adducted ammonium. As a result, as detailed in the Experimental section, reported CCS data were obtained by averaging over all relevant MD equilibrated configurations. Overall, signals observed in the two ATDs of Figure 3 could safely be assigned to ammonium adducts of $\alpha$-Glu- $5 \mathrm{~A}\left(\mathrm{t}_{\mathrm{D}}=5.2 \mathrm{~ms}\right)$ and $\beta$-Glu- $5 \mathrm{~A}\left(\mathrm{t}_{\mathrm{D}}=5.5\right.$ $\mathrm{ms})$. Based on these ESI-IMS-MS results, both DMAC and THF samples would contain the two Glu-5A anomers, which strongly contradicts ESI-MS/MS data, suggesting that only the THF sample would contain the Glu-5A $\alpha$ anomer.
Taking advantage of their IMS separation, CID of the two $\mathrm{m} / \mathrm{z} 468.2$ precursor ions was then performed after the mobility cell to record individual MS/MS spectra for each species. These ESI-IMS-MS/MS experiments were performed with the $m / z 468.2$ precursor ions first selected in the quadrupole mass analyzer, then injected in the TWIMS cell prior to being subjected to CID in the collision cell, and product ions measured with the oa-TOF mass analyzer. The first noticeable feature in the ATDs so-obtained is the presence of multiple signals in addition to the peaks expected at $t_{D}=5.2 \mathrm{~ms}$ for $[\alpha-$ Glu-5A $\left.+\mathrm{NH}_{4}\right]^{+}$and $\mathrm{t}_{\mathrm{D}}=5.5 \mathrm{~ms}$ for $\left[\beta-\mathrm{Glu}-5 \mathrm{~A}+\mathrm{NH}_{4}\right]^{+}$ (Figure 4). These additional peaks correspond to ions with $m / z 379.1\left(\mathrm{t}_{\mathrm{D}}=4.1 \mathrm{~ms}\right.$, red trace $), m / z 235.1\left(\mathrm{t}_{\mathrm{D}}=2.7 \mathrm{~ms}\right.$, pink trace), $m / z 181.1\left(\mathrm{t}_{\mathrm{D}}=2.3 \mathrm{~ms}\right.$, orange trace), and $m / z 109.1\left(\mathrm{t}_{\mathrm{D}}=1.5\right.$ $\mathrm{ms}$, blue trace), that is, the main product ions of $\left[\mathrm{Glu}-5 \mathrm{~A}+\mathrm{NH}_{4}\right]^{+}$. This indicates that the selected $\mathrm{m} / \mathrm{z} 468.2$ precursor ions have experienced uncontrolled and extensive fragmentation.

Owing to the experimental configuration used to obtain these data, where only $\mathrm{m} / \mathrm{z} 468.2$ ions were selected for injection in the TWIMS cell, product ions evidenced to be separated from their $\mathrm{m} / \mathrm{z} 468.2$ precursor ion were neither formed upon ion activation in the source region nor prior to the quadrupole analyzer. Moreover, these product ions were measured at similar drift times compared with fragments generated during experiments where the $m / z 468.2$ precursor ions were activated in the ion trap prior to entering the mobility cell (Supplementary Figure S5). As a result, it can be concluded that most uncontrolled fragmentation giving rise to the ATDs shown in Figure 4 did not occur as ions traveled the TWIMS cell (which would have yielded a distribution of their drift time) but as they entered it. These findings are consistent with results previously reported using the same Synapt G2 instrument, which showed that ion injection in the mobility cell could raise the internal temperature to about $550-800 \mathrm{~K}$, depending on the species $[11,12]$. Lowering voltages aimed at optimizing ion introduction in the mobility cell, as well as decreasing gas pressure in the $\mathrm{He}$ and in the mobility cells, allowed these fragmentations to be minimized to some extent but at the price of IMS separation of ammonium adducts of $\alpha$ - and $\beta$-Glu-5A (data not shown).
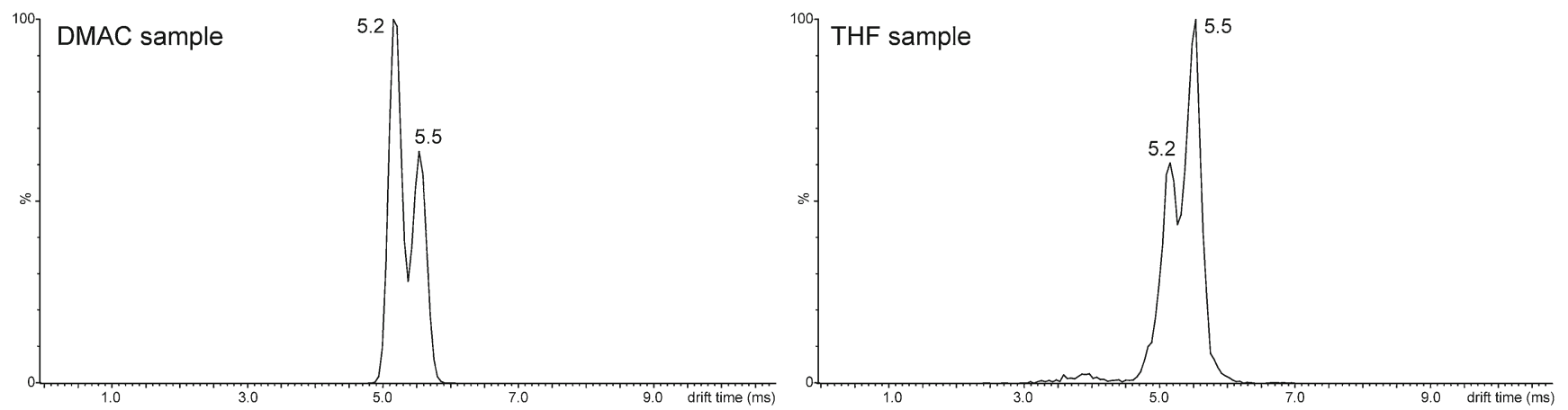

Figure 3. Arrival time distribution of [Glu-5A $\left.+\mathrm{NH}_{4}\right]^{+}$ions $(\mathrm{m} / \mathrm{z}$ 468.2) in IMS-MS experiments performed after electrospray ionization of the DMAC sample (left panel) and of the THF sample (right panel) 

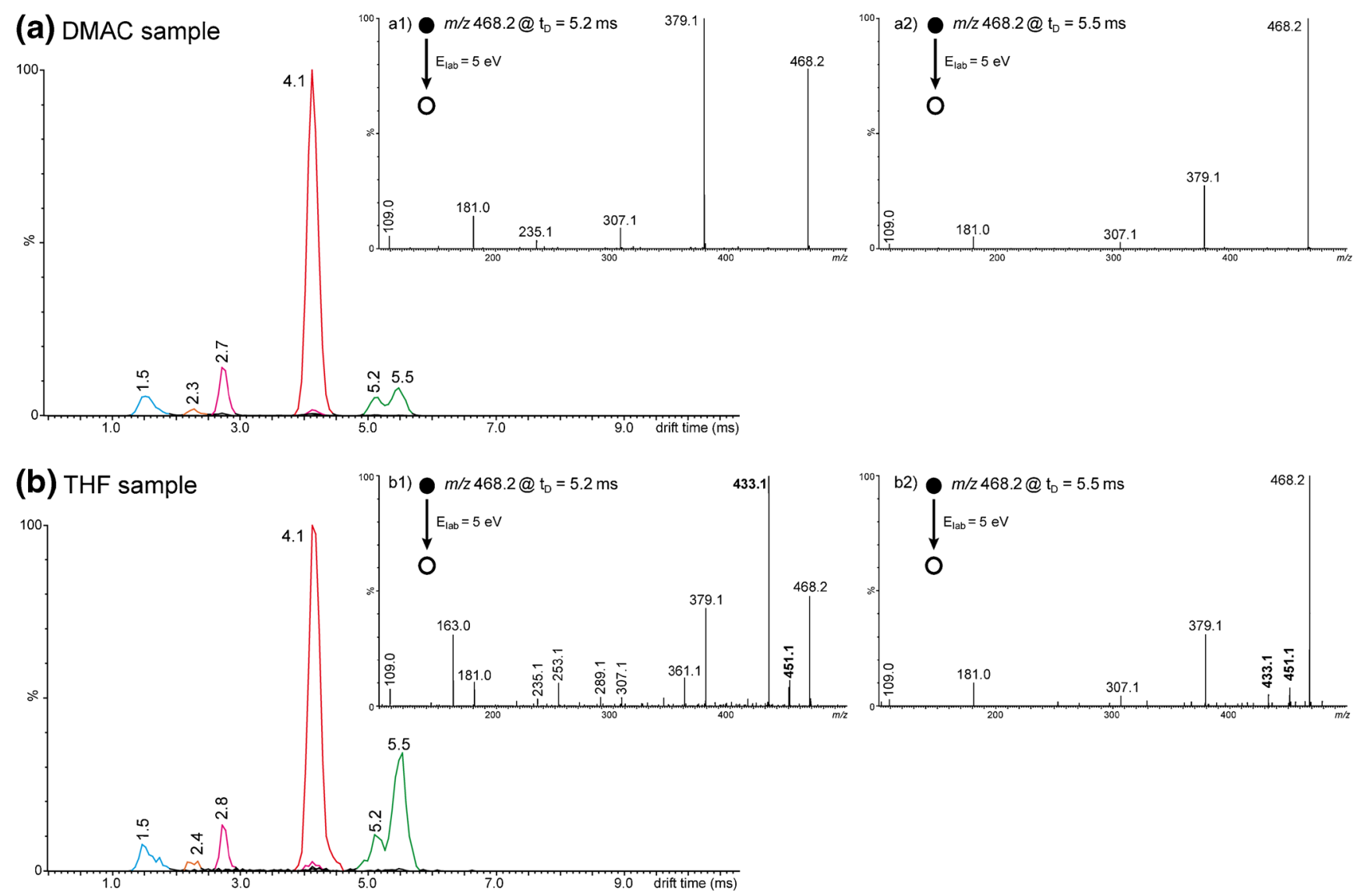

Figure 4. Arrival time distribution (ATD) of fragments generated from $\mathrm{m} / \mathrm{z} 468.2$ precursor ions subjected to IMS-MS/MS experiments after ESI of (a) the DMAC sample and (b) the THF sample. The green trace corresponds to the ATD of $m / z 468.2$ ions, which were detected at their expected $5.2 \mathrm{~ms}(\alpha-\mathrm{Glu}-5 \mathrm{~A})$ and $5.5 \mathrm{~ms}$ ( $\beta$-Glu-5A) drift times $\left(\mathrm{t}_{\mathrm{D}}\right)$. Additional IMS traces correspond to ions at $m / z 379.1$ ( $\mathrm{t}_{\mathrm{D}}=4.1 \mathrm{~ms}$, red), $\mathrm{m} / \mathrm{z} 235.1$ ( $\mathrm{t}_{\mathrm{D}}=2.7 \mathrm{~ms}$, pink), $\mathrm{m} / \mathrm{z} 181.1$ ( $\mathrm{t}_{\mathrm{D}}=2.3 \mathrm{~ms}$, orange), and $\mathrm{m} / \mathrm{z} 109.1$ ( $\mathrm{t}_{\mathrm{D}}=1.5 \mathrm{~ms}$, blue). Insets: MS/MS spectra extracted from the IMS peaks at $t_{D}=5.2 \mathrm{~ms}(\alpha-$ Glu- $5 \mathrm{~A})$ and at $t_{D}=5.5 \mathrm{~ms}(\beta-\mathrm{Glu}-5 \mathrm{~A})$

CID data extracted at the drift times assigned to the ammonium adducts of Glu-5A are shown as insets in Figure 4. MS/ MS spectra obtained for $\left[\beta-G l u-5 \mathrm{~A}+\mathrm{NH}_{4}\right]^{+}$at $\mathrm{t}_{\mathrm{D}}=5.5 \mathrm{~ms}$ were almost the same in both cases (Figure $4 \mathrm{a} 2$ and b2). Of note, because the two $\mathrm{m} / \mathrm{z} 468.2$ precursor ions were poorly resolved in IMS, extraction of pure MS/MS data of good quality was hard to achieve; as a result, the low intensity peaks at $\mathrm{m} / \mathrm{z} 451.1$ and 433.1 observed in Figure $4 \mathrm{~b} 2$ after extracting the $t_{D}=5.5 \mathrm{~ms}$ IMS peak actually arose from the nearly "co-eluting" $t_{D}=5.2$ $\mathrm{ms}$ compound. In contrast, MS/MS spectra recorded at the 5.2 ms drift time assigned to the ammonium adduct of $\alpha$-Glu- $5 \mathrm{~A}$ were very different depending on the solvent used in the synthesis. Although the $\mathrm{m} / \mathrm{z} 451.1$ (loss of $\mathrm{NH}_{3}$ ) and $\mathrm{m} / \mathrm{z}$ 433.1 (loss of $\mathrm{NH}_{3}+\mathrm{H}_{2} \mathrm{O}$ ) product ions were formed with high abundance when the precursor ion was electrosprayed from the THF sample (Figure 4b1), they were not detected in the ESI-IMS-MS/MS spectrum obtained from the DMAC sample (Figure 4a1). In other words, these ESI-IMS-MS/MS data indicate that the $5.2 \mathrm{~ms}$ IMS peak assigned to ammoniated $\alpha$-Glu-5A would actually correspond to different species depending on the solvent present in the synthesis medium. This last puzzling result could, however, be rationalized by considering the existence of two forms of the $\left[\alpha-\mathrm{Glu}-5 \mathrm{~A}+\mathrm{NH}_{4}\right]^{+}$differing in terms of ammonium location, based on previously discussed computed conformational data showing no significant difference between calculated CCS values as a function of the location of the ammonium cation adducted to each Glu-5A anomer. In other words, species observed at a $5.2 \mathrm{~ms}$ drift time in ATD of each sample would not be the same ammonium adducts of $\alpha$-Glu-5A. In the case of the THF sample, the [ $\alpha-$ Glu-5A $\left.+\mathrm{NH}_{4}\right]^{+}$ions detected after the IMS separation step would have the ammonium cation adducted to the acrylate moiety at C2 (hence allowing the proposed anchimerically assisted dissociation reaction depicted in Scheme 2, leading to $\mathrm{m} / \mathrm{z} 451.1$ and 433.1 product ions), and would be formed as the most stable species during the electrospray ionization step. In contrast, the $\left[\alpha-\mathrm{Glu}-5 \mathrm{~A}+\mathrm{NH}_{4}\right]^{+}$ions would hold the adducted cation at another acrylate moiety in the case of the DMAC sample. Noticeably, presence of $\left[\alpha-\mathrm{Glu}-5 \mathrm{~A}+\mathrm{NH}_{4}\right]^{+}$ ions was evidenced in the DMAC sample only when experiments involved an IMS step. Accordingly, we hypothesized that the $\alpha$-Glu-5A compound was not originally present in the DMAC sample (consistent with ESI-MS/MS data in Figure 1, bottom left) but would be generated upon collisional activation 


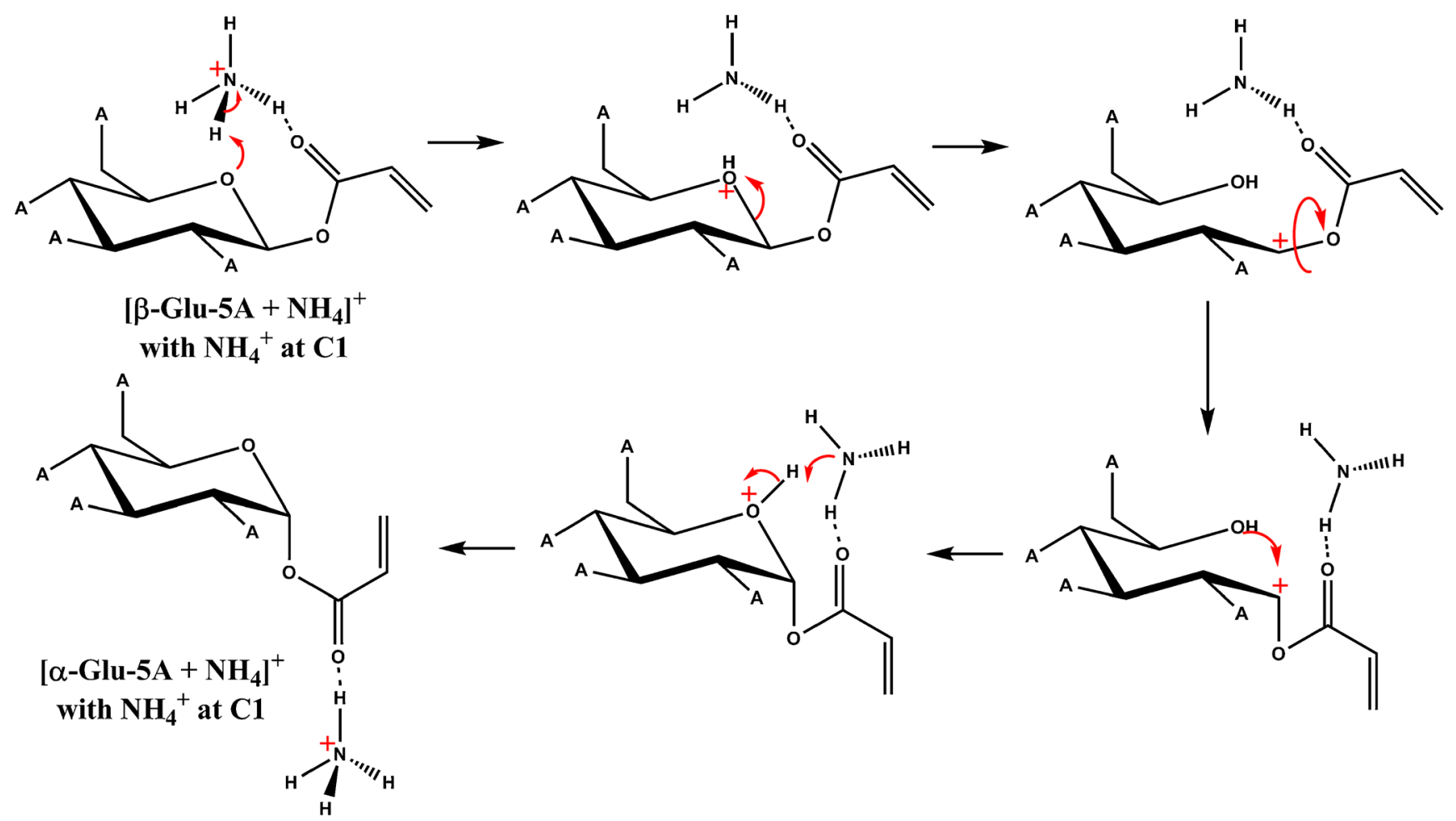

Scheme 3. Proposed mechanism for anomerization of ammoniated Glu-5A in the gas phase

of $\beta-$ Glu-5A at the entrance of the mobility cell. As depicted in Scheme 3 , such an anomerization reaction is proposed to occur in the gas phase, with the adducted ammonium playing the role usually endorsed by solvent molecules in the commonly reported liquid phase process.

To support the mechanism reported in Scheme 3, CP MD were performed. We began by simulating the glucose ring opening starting from the $\mathrm{C} 1$ ammonium adduct of Glu-5A in the $\beta$-configuration (Scheme 3, upper row). One picosecond of
CPMD simulation without metadynamics was carried out on the starting configuration to allow the system to equilibrate at finite temperature. During the equilibration stage, we observed that the oxygen atom of the glucose ring gets protonated by the nearby coordinated ammonium cation. To find the minimum energy pathway underlying this process, we then switched to metadynamics simulations. We defined two collective variables: CV1, which is the coordination number of the $\mathrm{C} 1$ with the ring oxygen, and $\mathrm{CV} 2$, representing the coordination

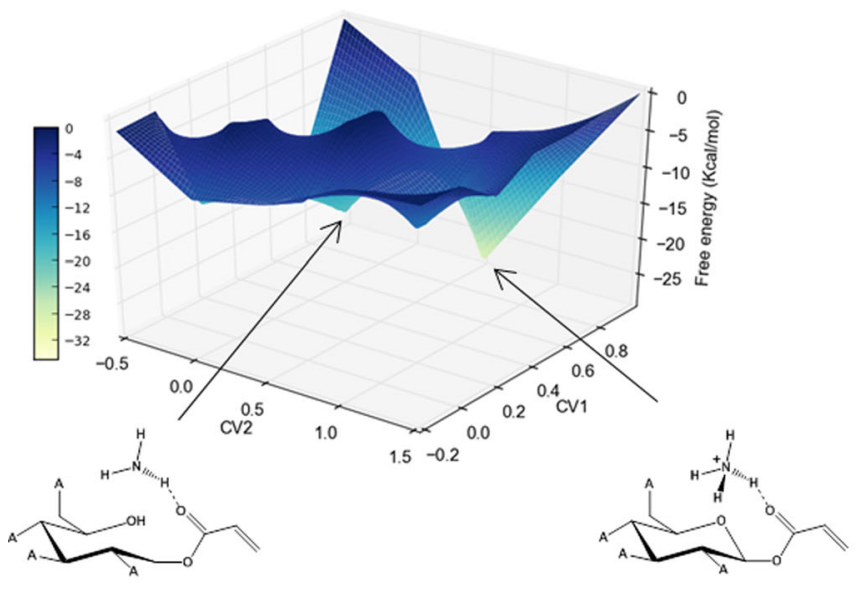

$-21.90 \mathrm{Kcal} / \mathrm{mol}$

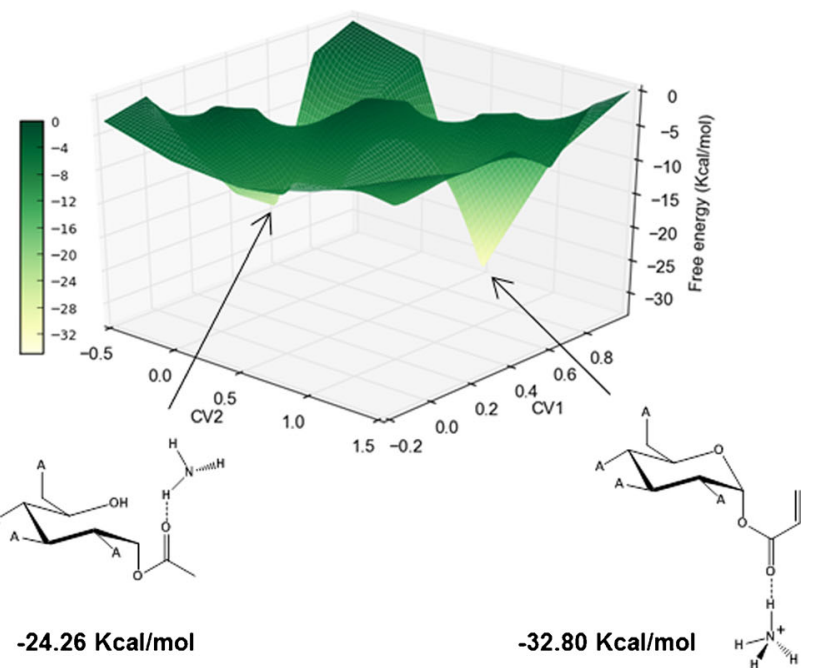

Figure 5. Free energy landscape for ring opening reaction of the ammonium adduct of $\beta-G$ lu-5A (left) and $\alpha-G$ lu-5A (right) obtained by metadynamics. The free energy values of the starting structures and the relevant carbocations are indicated by arrows. See main text for the definition of the collective variable CV1 and CV2 
number of the ring oxygen with respect to the hydrogen atoms of the ammonium group. The corresponding free energy surface of the $\beta$-Glu-5A ring opening, leading to the secondary carbocation with the acrylate substituent at $\mathrm{C} 1$ in equatorial orientation is shown in the left panel of Figure 5. The estimated free energy barrier for this process is $7.22 \mathrm{kcal} / \mathrm{mol}$, suggesting that collisional activation can likely catalyze the transformation of the glucose ring into its corresponding carbocation.

Next, we considered the analogous process starting from the $\mathrm{C} 1$ ammonium adduct of the $\alpha$-anomer of Glu-5A (Scheme 3, bottom row). In this case, the energy barrier of the ring opening reaction is $8.54 \mathrm{kcal} / \mathrm{mol}$ (Figure 5, right panel), also compatible with process activation in the considered environment. Most importantly, the free energy difference between the carbocation with the acrylate group in the equatorial position and that deriving from the opening of glucose with the substituent in the axial position is negative $(-2.36 \mathrm{kcal} / \mathrm{mol})$, and hence favorable. Therefore, according to our calculations, the conversion from $\beta$ - to $\alpha$-cation in the gas phase is a thermodynamically spontaneous process, ultimately leading to the formation of the $\alpha$-anomer of Glu-5A from $\beta$-Glu-5A.

The experiment described in Figure 4 was then performed, varying the energy used for injection of $\mathrm{m} / z 468.2$ precursor ions in the TWIMS cell and monitoring any modification of the two anomer signals as an additional evidence of the proposed $\beta$-Glu- $5 \mathrm{~A} / \alpha$-Glu-5A conversion (Supplementary Figure S6). However, even slight increases in the injection energy were observed to induce additional effects that can also account for variation of ion abundances, such as improvement in ion transmission and increase of fragmentation yield. While the former effect is expected to be similar for both species, the extent of dissociation was shown to be different for the two anomers (insets of Figure 4 ). As a result, the $\alpha / \beta$ intensity ratio could not be used to unambiguously evidence the $\beta \rightarrow \alpha$ anomeric conversion upon ion injection in the TWIMS cell.

Finally, in order to find out whether a similar anomerization process could also account for different MS/MS data obtained for partially acrylated glucose when prepared in different solvents, ammonium adducts of Glu-3A and Glu-4A were also subjected to IMS analysis. Unfortunately, $\alpha$ - and $\beta$-anomers of each of these two species could not be separated in IMS, consistent with theoretical calculation which demonstrated that (1) positional isomers of partially substituted glucose have indistinguishable CCS, independently of being in the $\alpha$ or $\beta$ form, and that (2) CCS values calculated for the $\alpha$ and $\beta$ forms differ by less than $0.6 \AA^{2}$, which is far below the $\pm 3 \AA^{2}$ experimental error evaluated in these IMS experiments (Supplementary Table S10).

\section{Conclusion}

This study showed that activation experienced by the ammonium adduct of $\beta$-Glu-5A while entering the TWIMS cell allowed its conversion into the $\alpha$-homologue. The only difference between ammonium adducts of $\alpha$-Glu-5A generated in the electrospray ionization source and those formed upon activation of $\beta$-Glu-5A at the entrance of the TWIMS cell was the location of the $\mathrm{NH}_{4}{ }^{+}$cation. These two forms could not be resolved in terms of CCS but they were distinguished in MS/ MS, thanks to an anchimerically assisted process occurring only from the electrosprayed $\alpha$-anomer with the ammonium adducted to the acrylate at $\mathrm{C} 2$, and not from the $\alpha$-anomer arising from gas phase conversion of $\beta$-Glu-5A, with the ammonium adducted to the acrylate at $\mathrm{C} 1$. This particular case greatly contrasts with most often reported examples where conformational changes induced by ion heating during the experiment were evidenced by IMS measurement while CID data remained unchanged. Nevertheless, the analytical configuration used here allowed us to unambiguously identify the stage, amongst the multiple possible ones (in the source region, upon injection in the TWIMS cell, during the mobility separation) at which the reported uncontrolled ion activation had occurred.

\section{Acknowledgments}

The authors acknowledge support for this work by the French Research Agency (grant number ANR-10-CDII-9). L.C. acknowledges support from Spectropole, the Analytical Facility of Aix-Marseille University, by allowing a special access to the instruments purchased with European Funding (FEDER OBJ2142-3341). L.C. thanks Dr. Olivier Ouari for helpful discussion. Access to CINECA supercomputing facility was granted through the sponsored HPC Italian Supercomputing Resource Allocation (ISCRA) projects SIMBIOSY (granted to S.P.).

\section{References}

1. Clemmer, D.E., Jarrold, M.F.: Ion mobility measurements and their applications to clusters and biomolecules. J. Mass Spectrom. 32, 577-592 (1997)

2. Wyttenbach, T., Bowers, M.T.: Gas-phase conformations: the ion mobility/ ion chromatography method. Mod. Mass Spectrom. 225, 207-232 (2003)

3. Kanu, A.B..., Dwivedi, P., Tam, M., Matz, L., Hill, H.H.: Ion mobilitymass spectrometry. J. Mass Spectrom. 43, 1-22 (2008)

4. Wyttenbach, T., Pierson, N.A., Clemmer, D.E., Bowers, M.T.: Ion mobility analysis of molecular dynamics. Ann. Rev. Phys. Chem. 65, 175-196 (2014)

5. Mason, E.A., McDaniel, E.W.: Transport propertie of ions in gases. Wiley, New York (1988), pp. 1-29

6. Henderson, S.C., Valentine, S.J., Counterman, A.E., Clemmer, D.E.: ESI/ ion trap/ion mobility/time-of-flight mass spectrometry for rapid and sensitive analysis of biomolecular mixtures. Anal. Chem. 71, 291-301 (1999)

7. Giles, K., Pringle, S.D., Worthington, K.R., Little, D., Wildgoose, J.L., Bateman, R.H.: Applications of a traveling wave-based radio-frequency only stacked ring ion guide. Rapid Commun. Mass Spectrom. 18, 24012414 (2004)

8. Shvartsburg, A.A., Smith, R.D.: Fundamentals of traveling wave ion mobility spectrometry. Anal. Chem. 80, 9689-9699 (2008)

9. Michaelevski, I., Eisenstein, M., Sharon, M.: Gas-phase compaction and unfolding of protein structures. Anal. Chem. 82, 9484-9491 (2010)

10. Morsa, D., Gabelica, V., De Pauw, E.: Effective temperature of ions in traveling wave ion mobility spectrometry. Anal. Chem. 83, 5775-5782 (2011)

11. Merenbloom, S.I., Flick, T.G., Williams, E.R.: How hot are your ions in TWAVE ion mobility spectrometry? J. Am. Soc. Mass Spectrom. 23, 553$562(2011)$ 
12. Morsa, D., Gabelica, V., De Pauw, E.: Fragmentation and isomerization due to field heating in traveling wave ion mobility spectrometry. J. Am. Soc. Mass Spectrom. 25, 1384-1393 (2014)

13. Ruotolo, B.T., Hyung, S.J., Robinson, P.M., Giles, K., Bateman, R.H., Robinson, C.V.: Ion mobility-mass spectrometry reveals long-lived, unfolded intermediates in the dissociation of protein complexes. Angew. Chem. Int. Ed. 46, 8001-8004 (2007)

14. Bush, M.F., Campuzano, I.D.G., Robinson, C.V.: Ion mobility mass spectrometry of peptide ions: effects of drift gas and calibration strategies. Anal. Chem. 84, 7124-7130 (2012)

15. Salbo, R., Bush, M.F., Naver, H., Campuzano, I., Robinson, C.V., Pettersson, I., Jorgensen, T.J.D., Haselmann, K.F.: Traveling-wave ion mobility mass spectrometry of protein complexes: accurate calibrated collision cross-sections of human insulin oligomers. Rapid Commun. Mass Spectrom. 26, 1181-1193 (2012)

16. Hawker, C.J., Bosman, A.W., Harth, E.: New polymer synthesis by nitroxide mediated living radical polymerizations. Chem. Rev. 101, 3661-3688 (2001)

17. Smith, D.P., Knapman, T.W., Campuzano, I., Malham, R.W., Berryman, J.T., Radford, S.E., Ashcroft, A.E.: Deciphering drift time measurements from traveling wave ion mobility spectrometry-mass spectrometry studies. Eur. J. Mass Spectrom. 15, 113-130 (2009)

18. Case, D.A., Babin, V., Berryman, J.T., Betz, R.M., Cai, Q., Cerutti, D.S., Cheatham, T.E., Darden, T.A., Duke, R.E., Gohlke, H., Goetz, A.W., Gusarov, S., Homeyer, N., Janowski, P., Kaus, J., Kolossváry, I., Kovalenko, A., Lee, T.S., LeGrand, S., Luchko, T., Luo, R., Madej, B., Merz, K.M., Paesani, F., Roe, D.R., Roitberg, A., Sagui, C., SalomonFerrer, R., Seabra, G., Simmerling, C.L., Smith, W., Swails, J., Walker, R.C., Wang, J., Wolf, R.M., Wu, X., Kollman, P.A.: AMBER 14. UCSF, San Francisco, CA, USA (2014)

19. Kirschner, K.N., Yongye, A.B..., Tschampel, S.M., Gonzalez-Outeirino, J., Daniels, C.R., Foley, B.L., Woods, R.J.: GLYCAM06: a generalizable biomolecular force field. Carbohydr. J. Comput. Chem. 29, 622-655 (2008)

20. Wang, J.M., Wolf, R.M., Caldwell, J.W., Kollman, P.A., Case, D.A.: Development and testing of a general amber force field. J. Comput. Chem. 25, 1157-1174 (2004)

21. Ryckaert, J.P., Ciccotti, G., Berendsen, H.J.C.: Numerical-integration of Cartesian equations of motion of a system with constraints - moleculardynamics of $N$-alkanes. J. Comput. Phys. 23, 327-341 (1977)

22. Wu, X.W., Brooks, B.R.: Self-guided Langevin dynamics simulation method. Chem. Phys. Lett. 381, 512-518 (2003)

23. Berendsen, H.J.C., Postma, J.P.M., Vangunsteren, W.F., Dinola, A., Haak, J.R.: Molecular-dynamics with coupling to an external bath. J. Chem. Phys. 81, 3684-3690 (1984)

24. Dear, G.J., Munoz-Muriedas, J., Beaumont, C., Roberts, A., Kirk, J., Williams, J.P., Campuzano, I.: Sites of metabolic substitution: investigating metabolite structures utilising ion mobility and molecular modelling. Rapid Commun. Mass Spectrom. 24, 3157-3162 (2010)

25. Mesleh, M.F., Hunter, J.M., Shvartsburg, A.A., Schatz, G.C., Jarrold, M.F.: Structural information from ion mobility measurements: effects of the longrange potential. J. Phys. Chem. 100, 16082-16086 (1996)

26. Siu, C.-K., Guo, Y., Saminathan, I.S., Hopkinson, A.C., Siu, K.W.M.: Optimization of parameters used in algorithms of ion-mobility calculation for conformational analyses. J. Phys. Chem. B 114, 1204-1212 (2010)

27. Available at: http://www.cpmd.org, Copyright IBM Corp 1990-2008, Copyright MPI [für Festkörperforschung] Stuttgart, (1997-2001)

28. Car, R., Parrinello, M.: Unified approach for molecular-dynamics and density-functional theory. Phys. Rev. Lett. 55, 2471-2474 (1985)

29. Perdew, J.P., Burke, K., Ernzerhof, M.: Generalized gradient approximation made simple. Phys. Rev. Lett. 77, 3865-3868 (1996)

30. Troullier, N., Martins, J.L.: Efficient pseudopotentials for plane-wave calculations. Phys. Rev. B 43, 1993-2006 (1991)

31. Kohn, W., Sham, L.J.: Self-consistent equations including exchange and correlation effects. Phys. Rev. 140, 1133-1138 (1965)
32. Humphrey, W., Dalke, A., Schulten, K.: VMD: visual molecular dynamics. J. Mol. Graph. Model. 14, 33-38 (1996)

33. Reichardt, C.: Solvents and solvent effects in organic chemistry, 3rd edn. Wiley-VCH, Weinheim (2003)

34. Angyal, S.J.: Conformational analysis in carbohydrate chemistry. I. Conformational free energies. The conformations and a:b ratio of aldopyranoses in aqueous solutions. Aust. J. Chem. 21, 2737-2746 (1968)

35. Angyal, S.J.: The composition and conformation of sugars in solution. Angew. Chem. Int. Ed. 8, 157-166 (1969)

36. Tvaroska, I., Bleha, T.: Anomeric and exoanomeric effects in carbohydratechemistry. Adv. Carbohydr. Chem. Biochem. 47, 45-123 (1989)

37. Shvily, R., Muller, T., Apeloig, Y., Mandelbaum, A.: Direct evidence for anchimeric assistance in alcohol elimination from gas-phase $\mathrm{MH}+$ ions of 1,4-dialkoxycyclohexanes under chemical ionisation. Experiment and theory. J. Chem. Soc. Perkin Trans. 2(6), 1221-1234 (1997)

38. Moraes, L.A.B..., Eberlin, M.N.: Structurally diagnostic ion-molecule reactions: acylium ions with alpha-, beta-, and gamma-hydroxy ketones. J. Mass Spectrom. 37, 162-168 (2002)

39. Ben Ari, J., Navon, I., Mandelbaum, A.: The effect of steric hindrance on the relative rates of anchimerically assisted alcohol eliminations from $\mathrm{MH}+$ ions of 2-substituted 1,4-dialkoxybutanes upon CI and CID-experiment and theory. Int. J. Mass Spectrom. 249, 433-445 (2006)

40. Chai, Y.F., Jiang, K.Z., Pan, Y.J.: Hydride transfer reactions via ion-neutral complex: fragmentation of protonated N-benzylpiperidines and protonated $N$-benzylpiperazines in mass spectrometry. J. Mass Spectrom. 45, 496-503 (2010)

41. Vijayakrishnan, B., Issaree, A., Corilo, Y.E., Ferreira, C.R., Eberlin, M.N., Peter, M.G.: MS $^{\mathrm{n}}$ of the six isomers of $(\mathrm{GlcN})(2)(\mathrm{GlcNAc})(2)$ aminoglucan tetrasaccharides (diacetylchitotetraoses): rules of fragmentation for the sodiated molecules and application to sequence analysis of heterochitooligosaccharides. Carbohydr. Polym. 84, 713-726 (2011)

42. Li, H.L., Giles, K., Bendiak, B., Kaplan, K., Siems, W.F., Hill, H.H.: Resolving structural isomers of monosaccharide methyl glycosides using drift tube and traveling wave ion mobility mass spectrometry. Anal. Chem. 84, 3231-3239 (2012)

43. Santos, J.J., Toma, S.H., Lalli, P.M., Riccio, M.F., Eberlin, M.N., Toma, H.E., Araki, K.: Exploring the coordination chemistry of isomerizable terpyridine derivatives for successful analyses of cis and trans isomers by travelling wave ion mobility mass spectrometry. Analyst 137, 4045-4051 (2012)

44. Revesz, A., Schroder, D., Rokob, T.A., Havlik, M., Dolensky, B.: In-flight epimerization of a bis-Troger base. Angew. Chem. Int. Ed. 50, 2401-2404 (2011)

45. Revesz, A., Schroder, D., Rokob, T.A., Havlik, M., Dolensky, B.: Identification and interconversion of diastereomeric oligo-Troger bases probed by ion mobility mass spectrometry. Phys. Chem. Chem. Phys. 14, 69876995 (2012)

46. Campuzano, I., Bush, M.F., Robinson, C.V., Beaumont, C., Richardson, K., Kim, H., Kim, H.I.: Structural characterization of drug-like compounds by ion mobility mass spectrometry: comparison of theoretical and experimentally derived nitrogen collision cross sections. Anal. Chem. 84, 10261033 (2012)

47. Domalain, V., Hubert-Roux, M., Lange, C.M., Baudoux, J., Rouden, J., Afonso, C.: Use of transition metals to improve the diastereomers differentiation by ion mobility and mass spectrometry. J. Mass Spectrom. 49, 423427 (2014)

48. Henderson, S.C., Li, J.W., Counterman, A.E., Clemmer, D.E.: Intrinsic size parameters for Val, Ile, Leu, Gln, Thr, Phe, and Trp residues from ion mobility. J. Phys. Chem. B 103, 8780-8785 (1999)

49. Gelb, A.S., Jarratt, R.E., Huang, Y., Dodds, E.D.: A study of calibrant selection in measurement of carbohydrate and peptide ion-neutral collision cross sections by traveling wave ion mobility spectrometry. Anal. Chem. 86, 11396-11402 (2014) 